\title{
Comparison and validation of global and regional ocean forecasting systems for the South China Sea
}

\author{
Xueming Zhu ${ }^{1}$, Hui Wang ${ }^{1}$, Guimei Liu ${ }^{1}$, Charly Régnier ${ }^{2}$, Xiaodi Kuang ${ }^{1}$, Dakui Wang ${ }^{1}$, Shihe Ren ${ }^{1}$, Zhiyou Jing ${ }^{3}$, \\ and Marie Drévillon ${ }^{2}$ \\ ${ }^{1}$ Key Laboratory of Research on Marine Hazards Forecasting, National Marine Environmental Forecasting Center, \\ Beijing, 100081, China \\ ${ }^{2}$ Mercator Océan, Ramonville Saint Agne, France \\ ${ }^{3}$ State Key Laboratory of Tropical Oceanography, South China Sea Institute of Oceanology, Chinese Academy of Sciences, \\ Guangzhou, 510301, China \\ Correspondence to: Guimei Liu (liugm@nmefc.gov.cn)
}

Received: 18 February 2016 - Published in Nat. Hazards Earth Syst. Sci. Discuss.: 25 February 2016

Revised: 25 May 2016 - Accepted: 17 June 2016 - Published: 20 July 2016

\begin{abstract}
In this paper, the performance of two operational ocean forecasting systems, the global Mercator Océan (MO) Operational System, developed and maintained by Mercator Océan in France, and the regional South China Sea Operational Forecasting System (SCSOFS), by the National Marine Environmental Forecasting Center (NMEFC) in China, have been examined. Both systems can provide sciencebased nowcast/forecast products of temperature, salinity, water level, and ocean circulations. Comparison and validation of the ocean circulations, the structures of temperature and salinity, and some mesoscale activities, such as ocean fronts, typhoons, and mesoscale eddies, are conducted based on observed satellite and in situ data obtained in 2012 in the South China Sea. The results showed that MO performs better in simulating the ocean circulations and sea surface temperature (SST), and SCSOFS performs better in simulating the structures of temperature and salinity. For the mesoscale activities, the performance of SCSOFS is better than MO in simulating SST fronts and SST decrease during Typhoon Tembin compared with the previous studies and satellite data; but model results from both of SCSOFS and MO show some differences from satellite observations. In conclusion, some recommendations have been proposed for both forecast systems to improve their forecasting performance in the near future based on our comparison and validation.
\end{abstract}

\section{Introduction}

The South China Sea (SCS, Fig.1) is the largest and deepest semi-enclosed marginal sea of the Northwest Pacific Ocean (NWP), with an area of about 3.5 million $\mathrm{km}^{2}$, and mean and maximum depth of about 1200 and $5300 \mathrm{~m}$, respectively. The northern SCS (NSCS) is a wide continental shelf with depth less than $200 \mathrm{~m}$, and the southern SCS (SSCS) is a large basin, comprising numerous islands, reefs, beaches, and shoals. SCS is connected with the adjacent seas through a number of channels, to the East China Sea in the north, to the NWP in the east, to the Sulu Sea in the southeast, and to the Java Sea in the south, by the Taiwan Strait (TWS), the Luzon Strait (LUS), the Mindoro Strait, the Balabac Strait, and the Karimata Strait, respectively. SCS has unique geographical features and rich marine mineral and petroleum resources; therefore it is very important for many countries around it.

The SCS is located in the East Asian Monsoon (EAM) winds regime; the northeasterly winds usually prevail with an average wind speed of $9 \mathrm{~m} \mathrm{~s}^{-1}$ over the whole domain in winter, while the southwesterly winds prevail with an average magnitude of $6 \mathrm{~m} \mathrm{~s}^{-1}$ dominating over the most parts of the SCS in summer (Hellerman and Rosenstein, 1983). The EAM is considered to be a major factor for driving the upper layer basin-scale circulation pattern in the entire SCS, showing an obvious seasonal variation, with a cyclonic gyre in winter and an anticyclonic gyre in summer (Wyrtki, 1961; Mao et al., 1999; Wu et al., 1999; Qu, 2000; Chu and Li, 


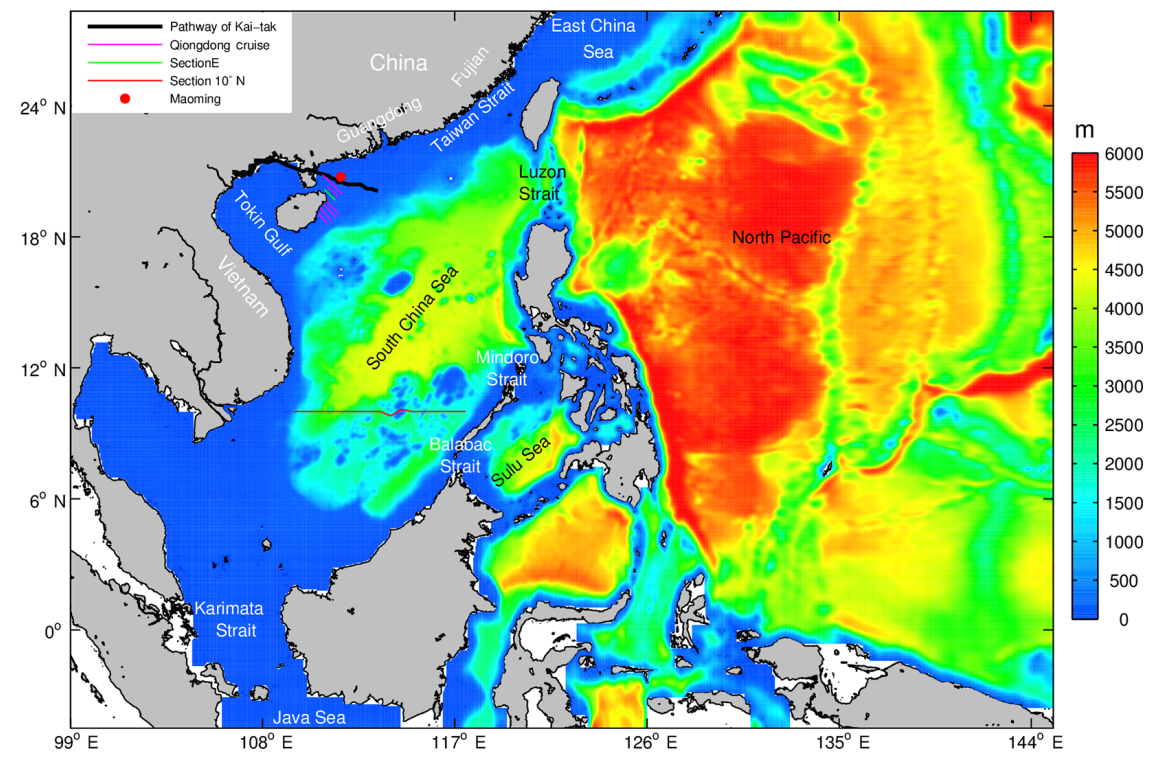

Figure 1. The model domain and bathymetry of SCSOFS.

2000). However, some other literature insists that a persistent cyclonic gyre is present in the NSCS, while a semiannual change from a cyclonic gyre in winter to an anticyclonic gyre regime in summer can be observed in the SSCS (Chao et al., 1996; Takano et al., 1998; Hu et al., 2000; Chern and Wang, 2003; Caruso et al., 2006; Chern et al., 2010). Chern et al. (2010) suggested that the three dynamical processes, the wind stress curl, the deep-water ventilation-induced vortex stretching in the central SCS, and a positive vorticity generated from the left flank of the Kuroshio in the LUS, play an equal role in the formation of the persistent cyclonic gyre in the NSCS, according to the analysis of the results from several numerical experiments with different wind stress, topography, and coastline.

In addition to the basin-scale circulations, there are still some sub-basin-scale currents in the SCS, such as the Guangdong Coastal Current (Huang et al., 1992), the SCS Warm Current (SCSWC, Guan, 1978; Chao et al., 1995), the Dongsha Coastal Current (DCC; Su, 2005), and the Luzon Coastal Current (LCC; Hu et al., 2000). However, there is still a lot of debate about the mechanisms of some of them among the studies reported by several authors, and no agreement has been reached. For example, based on the results of the numerical simulations, the formation dynamical mechanism of the SCSWC may be related to the Kuroshio intrusion ( $\mathrm{Li}$ et al., 1993; Cai and Wang, 1997), sea surface slope (Fang and Zhao, 1988; Guan, 1993), or the wind relaxation (Chao et al., 1995).

The Kuroshio intrudes into the SCS through the LUS, carrying the warm and salty water from the NWP, significantly affecting the circulation pattern and the budgets of heat and salt in the NSCS (Farris and Wimbush, 1996; Wu and Chiang, 2007; Liang et al., 2008; Nan et al., 2013). However, this is still not in accordance with how the Kuroshio intrudes into the NSCS. As pointed out in Hu et al. (2000), there were four main features of the Kuroshio intrusion as follows: a direct branch from the Kuroshio (Williamson, 1970; Fang et al., 1996; Chern and Wang, 1998; Qu et al., 2000), a form of loop (Zhang et al., 1995; Liu et al., 1996; Farris and Wimbush, 1996), a form of extension (Hu et al., 1999), and a form of ring (Li et al., 1998a, b) at present. Nan et al. (2015) reviewed and summarized the Kuroshio intruding processes from observed data, numerical experiments, and theoretical analyses, and concluded that there were three typical paths of the Kuroshio intruding the SCS, the looping path, the leaking path, and the leaping path, which could be distinguished quantitatively by a Kuroshio SCS Index (Nan et al., 2011a) derived from the integral of geostrophic vorticity southwest of Taiwan. The three paths can change from one to another over several weeks.

In addition, many mesoscale eddy activities are further obvious physical characteristics of the NSCS, and have significant influence in the dynamical environment of the NSCS. Eddies are generally more energetic than the surrounding currents, and are an important component of dynamical oceanography at all scales. In particular, they transport heat, mass, momentum, and biogeochemical properties from the regions where they are formed to remote areas where they can then impact budgets of heat, mass, momentum, and biogeochemical properties. Eddies in the NSCS have attracted increasing attention over recent decades. Much work has been done based on the combination of satellite observations and in situ hydrographic data (Wang and Chern, 1987; Li et al., 1998a; Chu et al., 1999; Wang et al., 2003; Hu et al., 2011; Nan et al., 2011b), or numerical models (Wu and Chiang, 2007; Xiu et al., 2010; Zhuang et al., 2010). Some 
work has focused on the statistical characteristics of eddies in the SCS, but eddies are greatly different from each other, causing different criteria for eddy identification to be employed by different literature (Wang et al., 2003; Xiu et al., 2010; Du et al., 2014). Some work has analyzed eddies' seasonal variability (Wu and Chiang, 2007; Zhuang et al., 2010) and investigated their origins (D. Wang et al., 2008). Some work has mainly studied specific eddies to better understand eddies' generation, development, and disappearance mechanisms (G. Wang et al., 2008; Zhang et al., 2013).

As shown above, the dynamic processes and relative mechanisms are very complex, and have still not been made clear until now in the SCS. It will be much more difficult to predict the future status of the ocean. National Marine Environmental Forecasting Center (NMEFC) is mainly responsible for the prediction of the mechanisms of the South China Sea, and has built a SCS Operational Forecasting System (SCSOFS). As is known to all, the open boundary forcing conditions play an important role in the numerical prediction of the regional ocean. Due to various limitations, the open boundary conditions (OBCs) of the current SCSOFS are derived from the Simple Ocean Data Assimilation (SODA, Carton and Giese, 2008) climatological monthly mean during the forecast run. This is extremely inappropriate for the realtime ocean prediction system, so we are planning to generate the $\mathrm{OBCs}$ from the real-time forecasting results derived from Mercator Océan (MO) to replace SODA in the next step, in order to further improve prediction accuracy of the SCSOFS. Before carrying out this work, it is necessary to compare and validate the performance of MO in the SCS.

This paper focuses on the comparison and validation of the performance of MO and SCSOFS in the SCS, based on the observation data we obtained in 2012. The rest of this paper is organized as follows. Section 2 gives an introduction to the observed data which are employed to validate the systems, as well as to the configurations of MO and SCSOFS. Section 3 shows the results of comparison and validation and discussions. Section 4 presents the summary and conclusions.

\section{Observed data and numerical operational systems}

\subsection{Satellite data}

The map of sea level anomaly (MSLA) and map of absolute dynamic topography data, with which the relative geostrophic velocity anomaly and absolute geostrophic velocity (AGV) data are derived, are used to analyze the mesoscale eddies in the SCS and compare with the numerical simulations. They are all-sat-merged and gridded delayedtime altimeter products produced by SSALTO/DUACS and distributed by Aviso in April 2014, with support from Centre National D'études Spatiales (Cnes, www.aviso.altimetry.fr). The products are directly computed on a $0.25^{\circ} \times 0.25^{\circ}$ spatial resolution Cartesian grid in both longitude and lati- tude, with a daily temporal resolution. Their period covers 1993 to the present, and the period of reference has been changed from 7 years (1993-1999) to 20 years (1993-2012). They have been corrected for instrumental errors, environmental perturbations, the ocean sea state influence, the tide influence, atmospheric pressure, and multi-mission crosscalibration (CLS, 2015).

Two kinds of sea surface temperature (SST) data are used in this paper. One type is derived from the merged satellite's infrared sensors (AVHRR/NOAA) and microwave sensor (AMSR-E/AQUA), and in situ SST (buoy and ship) data global daily SST (MGDSST), with a $0.25^{\circ} \times 0.25^{\circ}$ horizontal resolution, which are analyzed and published at the Office of Marine Prediction of the Japan Meteorological Agency (JMA). The data can be obtained from http://near-goos1. jodc.go.jp/.

The other type is derived from the NOAA $0.25^{\circ} \times 0.25^{\circ}$ daily optimum interpolation sea surface temperature (OISST), which is an analysis constructed by combining observations from different platforms, such as satellites, ships, and buoys, on a regular grid via optimum interpolation. Currently, National Centers for Environmental Information (NCEI) provides two kinds of OISST: one uses infrared satellite data from the Advanced Very High Resolution Radiometer (AVHRR), named AVHRR-only, and the other one uses AVHRR data along with microwave data from the Advanced Microwave Scanning Radiometer (AMSR) on the Earth Observing System Aqua or AMSR-E satellite, named AVHRR+AMSR. Since the production of the AVHRR+AMSR data ended in 2011, the first one, AVHRR-only, is used in this study, which spans 1981 to the present and can be downloaded from the website; http://www.ncdc.noaa.gov/oisst/data-access.

\subsection{In situ data}

The in situ data employed in this paper for the comparison and validation of both systems are provided by the South China Sea Institute of Oceanology, Chinese Academy of Sciences. There was one mooring to measure the sea water velocity and five cruises conducted to measure the temperature and salinity (TS) in the SCS during 2012.

The mooring station is located at Maoming (Fig. 1), where bottom-mounted upward-looking $75 \mathrm{kHz}$ acoustic Doppler current profilers (ADCPs) were deployed to monitor the current profile ( $\mathrm{u}$ component and $\mathrm{v}$ component) from the depth of 2 to $48 \mathrm{~m}$ with a $2 \mathrm{~m}$ vertical interval. The period of the monitoring is from 11 July to 8 October 2012, with a temporal interval of $10 \mathrm{~min}$. Firstly, the outlier data are eliminated from the original measured data; secondly, a $25 \mathrm{~h}$ low-pass filter is applied to remove tidal currents; and daily mean currents are calculated using $25 \mathrm{~h}$ averaging. After that, the measured $\mathrm{u}$ and $\mathrm{v}$ components are used to compare and validate the simulated results of MO and SCSOFS. 
The TS data from the five cruises were measured by the SeaBird 19 plus CTD (conductivity, temperature, and depth) instrument with $1 \mathrm{~m}$ vertical resolution. Among the five cruises, one is the Qiongdong cruise in the NSCS, which was conducted for 9 days from 12 to 20 July at 90 stations along six sections (see Fig. 1); another one is the Nansha cruise around the Nansha Islands, which was conducted for 5 days from 24 to 28 August at 17 stations along a $10^{\circ} \mathrm{N}$ section from 109.5 to $117.5^{\circ} \mathrm{E}$. The TS data from these two cruises will be used to compare and validate the TS distribution from MO and SCSOFS in the vertical and horizontal. The TS data collected from all five cruises will be used to perform a correlation analysis of each of the simulated predictions of MO and SCSOFS models with the observations.

\subsection{The configurations of SCSOFS}

The SCSOFS is built based on the Regional Ocean Modeling System (ROMS). ROMS is a 3-D, nonlinear primitive equations, free-surface, hydrostatic, split-explicit, topographyfollowing-coordinate in the vertical, and orthogonal curvilinear in the horizontal on a staggered Arakawa C-grid (Arakawa and Lamb, 1977) oceanic model (Shchepetkin and McWilliams, 2005).

To avoid the influences of boundaries on the circulations in the SCS, the model's boundaries were extended southward and eastward; then the model covered a larger domain $\left(4.5^{\circ} \mathrm{S}\right.$ to $28.3^{\circ} \mathrm{N}, 99$ to $145^{\circ} \mathrm{E}$, Fig. 1) than the SCS. The horizontal resolution variates from $1 / 12^{\circ}$ in the south and east boundary to $1 / 30^{\circ}$ in the SCS. There were $36 \mathrm{~s}-$ coordinate levels in the vertical, with the thinnest layer being $0.16 \mathrm{~m}$ on the surface. The bathymetry was extracted from the ETOPO1 datasets published by US National Geophysical Data Center (NGDC), which is a global relief model of Earth's surface that integrates ocean bathymetry and land topography, with 1 arcmin resolution (Amante and Eakins, 2009). The ETOPO1 dataset has combined the satellite altimeter observations, shipping load sonar measurements, a multi-resolution digital terrain database and the global digital terrain model, and many other data sources, and it has been widely used in the global and regional oceanic models. Additionally, the original ETOPO1 bathymetry was revised in the area near the coast of mainland China, according to the in situ data collected in NMEFC, then smoothed according to Shapiro (1975). The maximum depth was set to be $6000 \mathrm{~m}$ and the minimum depth to be $10 \mathrm{~m}$ in the model (Wang, 1996).

The initial temperature and salinity conditions were derived from the climatology monthly mean SODA in January. However, the initial velocities and elevation were set to zero, which means the model was integrated from a static status. The model's western lateral boundary was treated as a wall. The other three (northern, southern, eastern) lateral boundaries were opened, whose temperature, salinity, velocity, and elevation were prescribed by spatial interpolation of the monthly mean SODA dataset. The 2-D and 3-D velocities, through the open boundaries, are modulated to guarantee the conservation of volume flux in the whole model domain. In addition, the nudging technology was used for 3-D velocity, temperature, and salinity to the three open lateral boundaries with a 30-day timescale for outflow and 3-day timescale for inflow.

The model is forced using 6-hourly wind stress, net fresh water fluxes, net heat fluxes, and surface solar shortwave radiation at surface from NCEP_Reanalysis 2 data provided by the NOAA/OAR/ESRL PSD, Boulder, Colorado, USA, accessible from the website at http://www.esrl.noaa.gov/psd/ (Kanamitsu et al., 2002). In order to get more reasonable simulated SST, the kinematic surface net heat flux sensitivity to $\operatorname{SST}(d Q / \mathrm{dSST})$ is used to introduce thermal feedback to correct net surface heat flux (Barnier et al., 1995), with a constant number $-30 \mathrm{~W} \mathrm{~m}^{2}$ degree $^{-1}$ in the whole domain. The MGDSST data are used to correct net surface heat flux. In addition, the monthly mean climatology discharges of the Mekong River and the Pearl River are prescribed to the model.

The system was run with $6 \mathrm{~s}$ time step for the external mode, and $180 \mathrm{~s}$ for the internal mode under the initial conditions, boundary conditions, and surface forcing mentioned in above. The system conducted a hindcast run from 2000 to 2011 after a 15 -year climatology run for spin-up (Wang et al., 2012). The instantaneous model results were archived with a 5-day interval, which were used as the ensemble members for the EnOI (Ensemble Optimal Interpolation) method assimilation. After the hindcast run, the system conducted an assimilation run in 2012 using the EnOI method; the alongtrack SLA data from AVISO had been assimilated as the observations with a 7-day time window. Details of the EnOI applied in SCSOFS can be referred to in Ji et al. (2015). The daily-averaged assimilated results were archived during the assimilation run, and were compared and validated in this paper. The system has been implemented into operations in NMEFC since 1 January 2013. It runs on a daily basis for 6-day simulations (1-day nowcast and 5-day forecast) to provide $120 \mathrm{~h}$ forecasting products of 3-D ocean temperature, salinity, and currents with a $24 \mathrm{~h}$ interval.

\subsection{The configurations of MO}

The high-resolution global analysis and forecasting system PSY4V1R3 was operational as the MyOcean project V2 from February 2011 up to April 2013, when it was replaced by the PSY4V2R2 system.

During this period, PSY4V1R3 produced weekly 14day hindcasts and daily 7-day forecasts. The PSY4V1R3 configuration described as follows indicates the MO model throughout this paper. The model configuration of PSY4V1R3 is based on a tripolar ORCA grid type (Madec and Imbard, 1996) in the NEMO (Nucleus for European Modelling of the Ocean) 1.09 version model with a $1 / 12^{\circ}$ 
horizontal resolution which means $9 \mathrm{~km}$ at the Equator, $7 \mathrm{~km}$ at midlatitudes, and $2 \mathrm{~km}$ toward the Ross and Weddell Sea. The grid cells follow an Arakawa C-grid type. The 50-level vertical discretization retained in this system has a $1 \mathrm{~m}$ resolution at the surface, decreasing to $450 \mathrm{~m}$ at the bottom and 22 levels within the upper $100 \mathrm{~m}$. "Partial cell" parametrization was chosen for a better representation of the topographic floor (Barnier et al., 2006). The high-frequency gravity waves are filtered out by the free surface formulation of Roullet and Madec (2000).

For the diffusion, a horizontal bilaplacian was added along the Equator $\left(20 \mathrm{~m}^{2} \mathrm{~s}^{-1}\right)$ and two laplacians in the Canadian straits (up to $100 \mathrm{~m}^{2} \mathrm{~s}^{-1}$ ). Laplacian lateral isopycnal diffusion was added to tracers $\left(125 \mathrm{~m}^{2} \mathrm{~s}^{-1}\right)$ and a horizontal bilaplacian viscosity was added for the momentum $\left(-1.0 \times 10^{10} \mathrm{~m}^{2} \mathrm{~s}^{-1}\right.$ at the Equator and decreasing poleward as the cube of the grid size). In addition, the vertical mixing is parameterized according to a turbulent closure model (order 1.5) adapted by Blanke and Delecluse (1993); the lateral friction condition is a partial-slip condition with a regionalization for the Mediterranean Sea, Indonesian region, Canadian straits, and Cape Horn. The atmospheric fields are taken from the ECMWF (European Centre for Medium Range Weather Forecasts) Integrated Forecast System at a daily average frequency. Momentum and heat turbulent surface fluxes are computed from CLIO bulk formulae (Goosse et al., 2001). A viscous-plastic rheology formulation is used for the LIM2_VP ice model (Fichefet and Maqueda, 1997; LIM2_VP in Hunke and Dukowicz, 1997). A multivariate data assimilation (Kalman Filter kernel with SEEK formulation; Pham et al., 1998) of in situ temperature (T) and salinity (S) (from Coriolis/Ifremer), along-track MSLA (from AVISO, with MDT from Rio and Hernandez, 2004), and intermediate resolution SST $\left(0.25^{\circ} \times 0.25^{\circ} \mathrm{SST}\right.$ product RTG from NOAA) is performed with the SAM2 software (Lellouche et al., 2013). An Incremental Analysis Update (IAU) centered on the fourth day of the 7-day assimilation window ensures a smooth correction of $T, \mathrm{~S}, \mathrm{U}, \mathrm{V}$, and SSH (sea surface height). The assimilation cycle consists of a first 7-day simulation called guess or forecast, at the end of which the analysis takes place. The IAU correction is then computed and the model is re-run on the same week, progressively adding the correction. The increment is distributed in time with a Gaussian shape which is centered on the fourth day. More details on the SAM2 software (applied on other model configurations) can be found in Lellouche et al. (2013) except that no large-scale bias correction is applied in PSY4V1R3. Concerning the initial conditions, the PSY4V1R3 was started in April 2009 from a 3-D climatology of temperature and salinity (WOA2005, Antonov et al., 2006; Locarnini et al., 2006).

\section{Comparisons, validations, and discussion}

\subsection{Velocities}

\subsubsection{Absolute geostrophic velocity}

Figure 2 shows the distributions of the monthly AGV composited with SSH from AVISO, MO, and SCSOFS in January, April, July, and October 2012, respectively. Here we use the January, April, July, and October to represent winter, spring, summer, and fall, respectively. It is valuable to note that the AGV of MO and SCSOFS are not the velocities' output from the numerical model directive. However, for a better comparison, they are recalculated according to SSH from the model output from each day and assuming geostrophic balance following Eq. (1):

$$
\begin{aligned}
& u=-\frac{g}{f} \frac{\partial \mathrm{SSH}}{\partial y} \\
& v=\frac{g}{f} \frac{\partial \mathrm{SSH}}{\partial x},
\end{aligned}
$$

where $g$ is gravitation acceleration, $f$ is the Coriolis parameter, $x, y$ are the east, north axis; $u, v$ are the eastward, northward velocity components in the horizontal, respectively.

Comparisons of the observations of AVISO with the results from MO and SCSOFS show that both MO and SCSOFS can detect the main basin-scale oceanic circulation pattern in the SCS, and show that there is a cyclonic gyre in winter and an anticyclonic gyre in summer, which is well in accordance with the pattern of AVISO. It is worth mentioning that the result of MO is in good agreement with the AVSIO in January, such as the southward western boundary currents along the eastern coast of Vietnam, the LCC, the anticyclonic eddy in the west of the LUS around $\left(118^{\circ} \mathrm{E}, 21^{\circ} \mathrm{N}\right)$, the cyclonic eddy in the east of Vietnam around $\left(113^{\circ} \mathrm{E}, 15^{\circ} \mathrm{N}\right)$. However, the result of SCSOFS is much smoother without obvious mesoscale or small-scale circulations, or they are much weaker $\left(0.2-0.4 \mathrm{~m} \mathrm{~s}^{-1}\right)$ than those $\left(0.6-0.8 \mathrm{~m} \mathrm{~s}^{-1}\right)$ of AVISO or MO. The circulation is chaos in spring in the SCS, though the circulation pattern of $\mathrm{MO}$ is in better agreement with the one of AVISO than the one from SCSOFS. The anticyclonic eddy around $\left(111^{\circ} \mathrm{E}, 10^{\circ} \mathrm{N}\right)$ and the western boundary jet in the southeast of Vietnam in summer, with the maximum speed being about $1.0 \mathrm{~m} \mathrm{~s}^{-1}, 0.9 \mathrm{~m} \mathrm{~s}^{-1}$, and $0.7 \mathrm{~m} \mathrm{~s}^{-1}$, are shown by AVISO, MO, and SCSOFS, respectively. The westward intensification along the eastern coast of Vietnam is more obvious in fall than the other three seasons, and the maximum speed is larger than $1.0 \mathrm{~m} \mathrm{~s}^{-1}$ for $\mathrm{MO}$ and $\mathrm{SC}$ SOFS, but is about $0.7 \mathrm{~m} \mathrm{~s}^{-1}$ for AVISO.

As mentioned in Sect. 1, the Kuroshio intruding the SCS through the LUS has been distinguished by three types as the looping path, the leaking path, and the leaping path, according to Nan et al. (2011a). All three results show the looping path in winter, the leaping path in summer, and the leaking path in fall, which is well consistent with the model results 

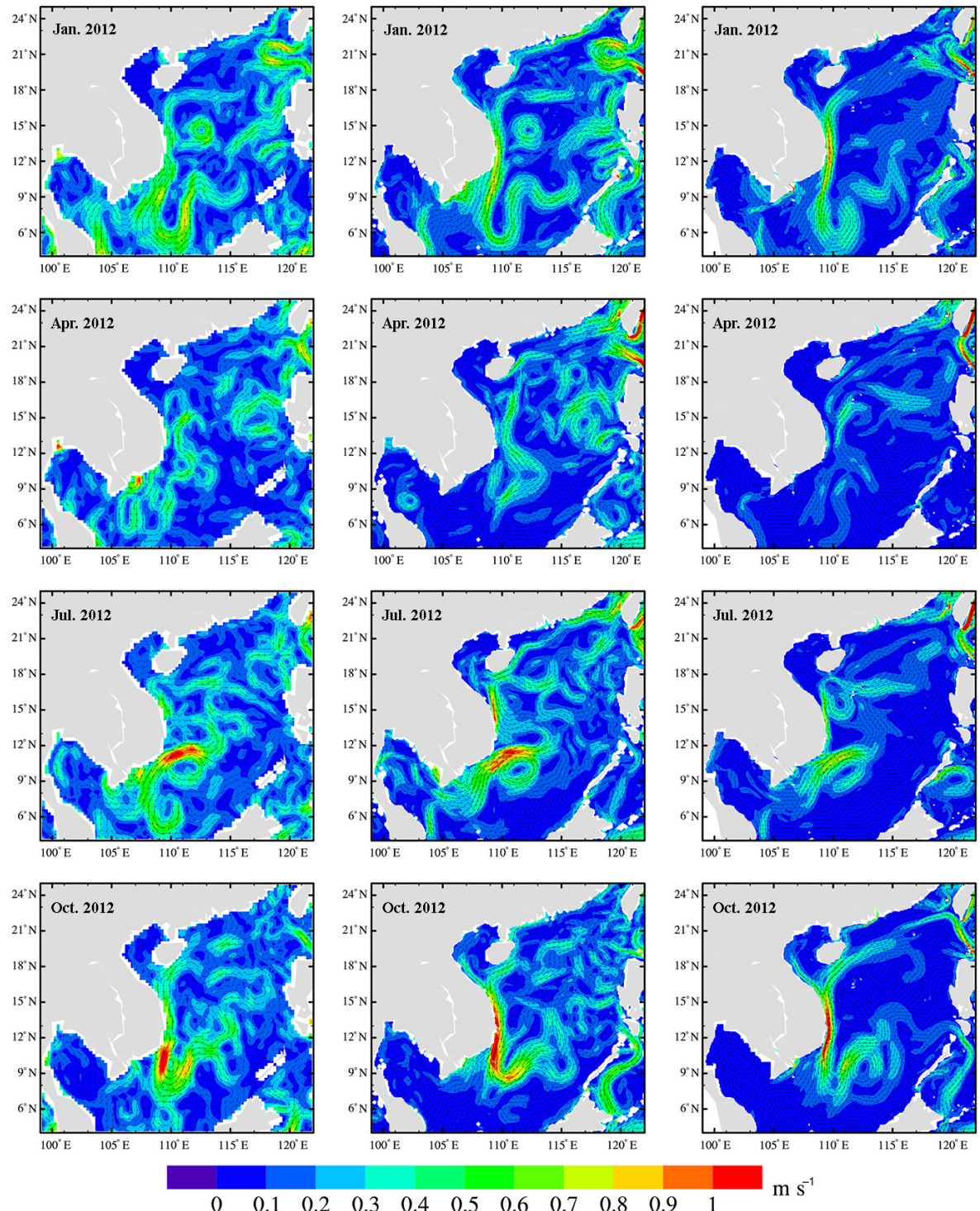

Figure 2. The monthly mean sea surface absolute geostrophic velocity (units: $\mathrm{m} \mathrm{s}^{-1}$ ) in January, April, July, and October 2012 . The left panels are from AVISO, the middle panels are from Mercator Océan, and the right panels are from SCSOFS.

shown by Wu and Chiang (2007). However, AVISO, MO, and SCSOFS show the leaking path, looping path, and leaping path in spring, respectively.

\subsubsection{Time series from the mooring station}

Figure 3 shows the comparison of the daily mean time series of $u, v$ components from the mooring, MO, and SCSOFS at $40 \mathrm{~m}$ depth layer at the Maoming station (see Fig. 1) from 11 July to 8 October 2012. Both MO and SCSOFS can capture the similar variation trends of the time series with the mooring observation. Especially MO results match the observed current variations well for both $u$ and $v$ components, during the period of Typhoon Kai-tak on 17 August 2012. Although SCSOFS shows larger velocity during Typhoon Kai- tak, the maximum velocity range is less than the observation and anticipating the observation about 1 day. The root mean square errors (RMSEs) between observations and models of MO and SCSOFS are $0.075 \mathrm{~m} \mathrm{~s}^{-1}$ and $0.094 \mathrm{~m} \mathrm{~s}^{-1}$ for the $u$ component, and $0.062 \mathrm{~m} \mathrm{~s}^{-1}$ and $0.084 \mathrm{~m} \mathrm{~s}^{-1}$ for the $v$ component, respectively. Overall, MO results are in better agreement with the observations than SCSOFS. SCSOFS results have a temporal bias (phase shift) compared with the observations. The phase of $u$ and $v$ components from SCFOFS results is leading the observations by about 1 day. 


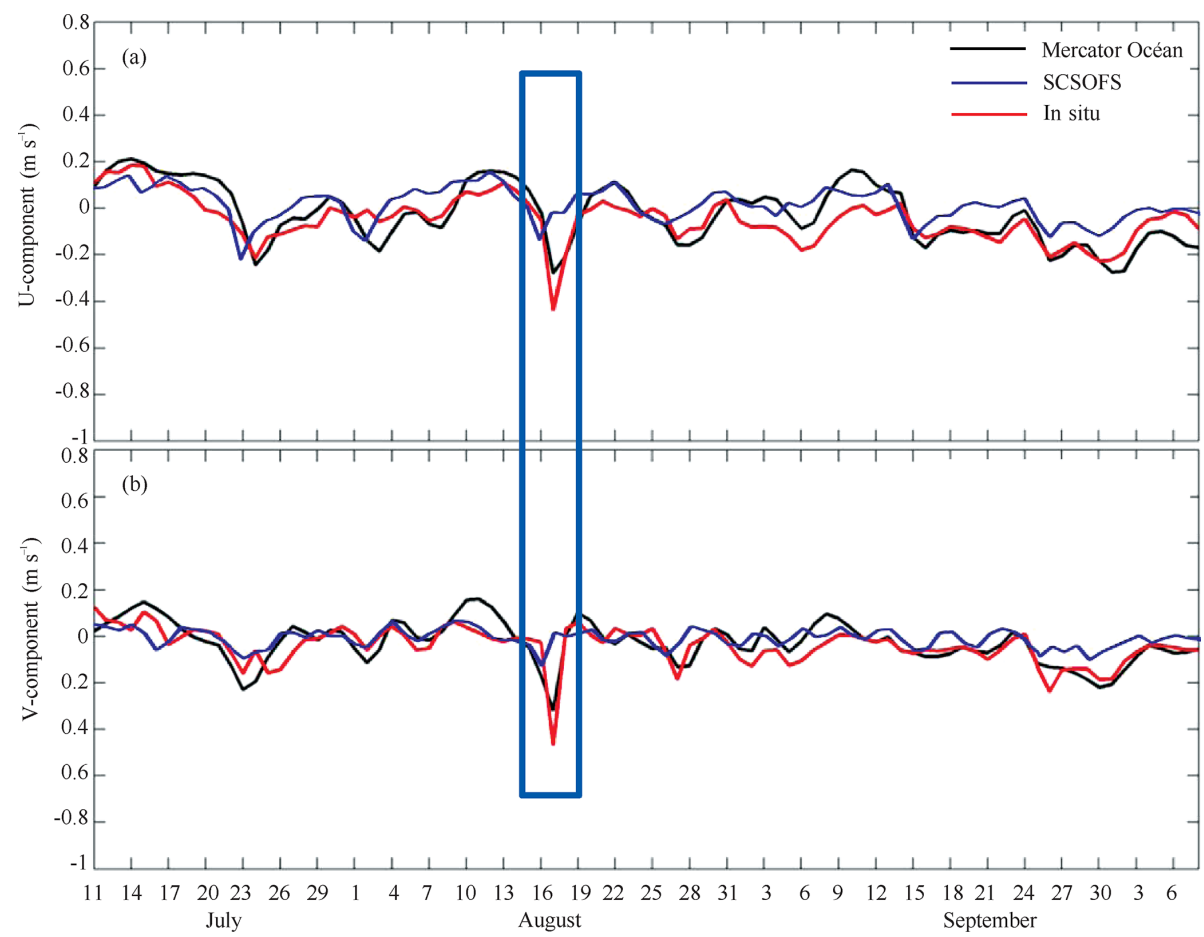

Figure 3. The daily mean time series of $u$ (a) and $v$ (b) components in $40 \mathrm{~m}$ depth layer at the Maoming mooring station, from in situ observations, Mercator Océan, and SCSOFS data.

\subsection{Temperature and salinity}

\subsubsection{SST}

SST is a very important prognostic variable in a hydrostatic ocean general circulation numerical model, which plays a key role in the ocean circulations and the air-sea interaction. Therefore, SST error is a crucial criterion of the numerical model skill, especially for an operational ocean circulation model. In fact, the SST simulation error is affected by several factors, for example the limitation of physical model, the surface atmospheric forcing conditions, the bias of initial field, and the uncertainty from the open boundary, as pointed out by Ji et al. (2015). Although the SST data have been assimilated into both MO and SCSOFS, the assimilated SST still has some errors for both systems.

Figure 4 shows the distributions of the monthly mean SST errors between two systems and MGDSST in the SCS in 2012. The errors show an obvious regional distribution; the larger errors mainly appear in the coastal regions for depths shallower than $200 \mathrm{~m}$, such as in the TWS, the east of the Guangdong province in January, and the Gulf of Tonkin in July. The strong seasonal variations for the basin-averaged SST error can also be found, which is larger in winter and smaller in summer for both systems. Comparing with MGDSST, the maximum, minimum, and mean for the basinaveraged 12 monthly RMSEs are $0.78,0.37$, and $0.51^{\circ}$ for the MO, $1.15,0.56$, and $0.86^{\circ}$ for the SCSOFS, respectively, in the SCS. Based on the Fig. 4, MO performed better than SCSOFS in simulating SST in comparison to MGDSST.

\subsubsection{Horizontal and vertical distribution of TS}

TS horizontal distributions at $10 \mathrm{~m}$ depth layer in the east of Hainan island from the in situ observations of Qiongdong cruise, model results from MO, and SCSOFS are shown in Fig. 5. Two clear cold and salty water cores located to the east of Hainan island, which are located at about $\left(110.75^{\circ} \mathrm{E}\right.$, $\left.19.2^{\circ} \mathrm{N}\right)$ and $\left(111.3^{\circ} \mathrm{E}, 19.7^{\circ} \mathrm{N}\right)$, are shown in both in situ observations and SCSOFS (Fig. 5), with the cores from SCSOFS being more saline than the in situ observations. It can be easily deduced that the two cores are produced by the upwelling process from the TS vertical distributions of sections $\mathrm{K}, \mathrm{F}, \mathrm{H}$, and $\mathrm{G}$ (Jing et al., 2015).

Figure 6 shows the vertical TS distributions from the in situ observations of Qiongdong cruise and model results from MO and SCSOFS, along section E. Both systems have similar vertical structures of TS to the in situ observations. All of them demonstrated the obvious upwelling systems, with cold and salty waters flowing from offshore to nearshore along the bottom. All three results show the upper mixing layer depth is about $15 \mathrm{~m}$. The seawater is well mixed above $15 \mathrm{~m}$ depth, and the isotherms and isohalines are almost vertical where strong vertical stratification is shown in summer. The diluted water flushes from the nearshore to offshore locations, with the 33-isohaline cross with the sea surface at the 

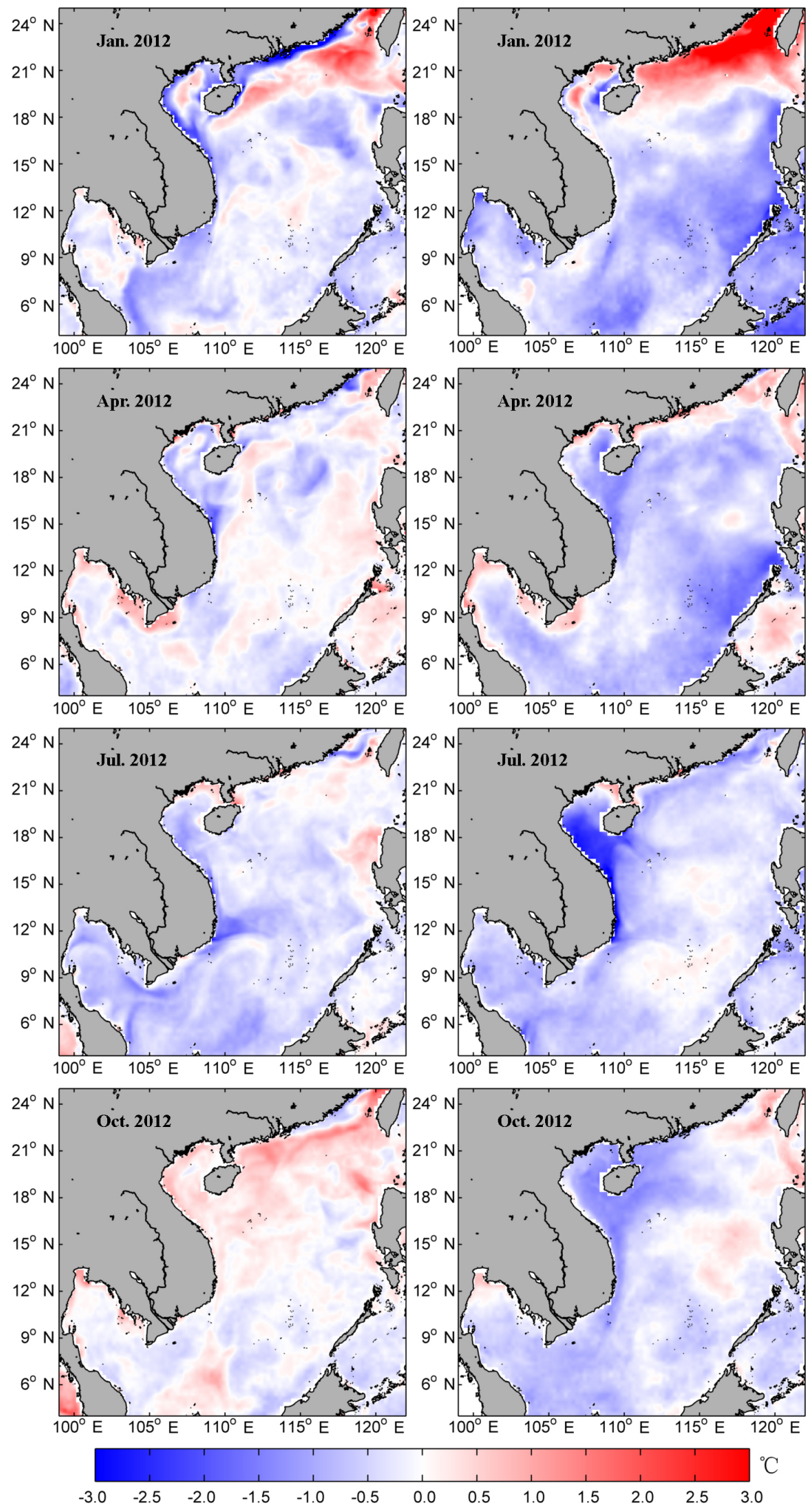

Figure 4. The monthly mean SST error between Mercator Océan (left panels), SCSOFS (right panels), and MGDSST in January, April, July, and October 2012. 

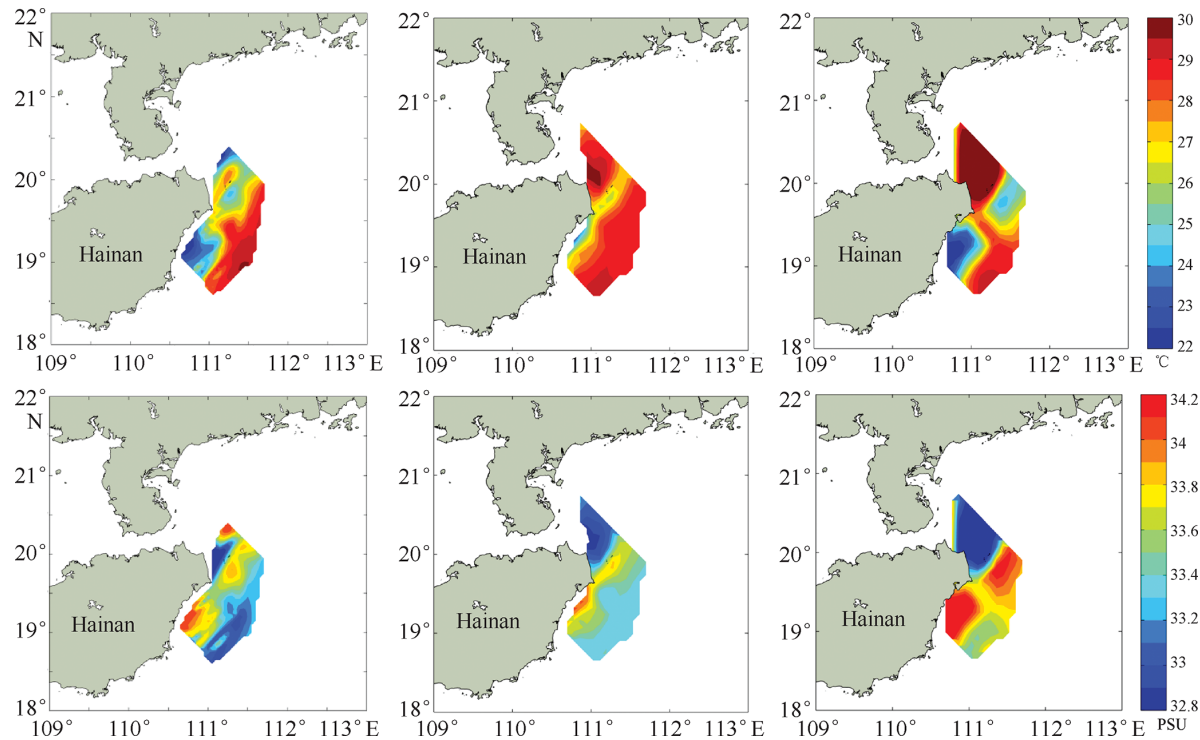

Figure 5. The horizontal distributions of temperature (upper panels) and salinity (lower panels) at $10 \mathrm{~m}$ depth layer from the in situ observations of Qiongdong cruise (left column), Mercator Océan (middle column), and SCSOFS (right column), respectively.
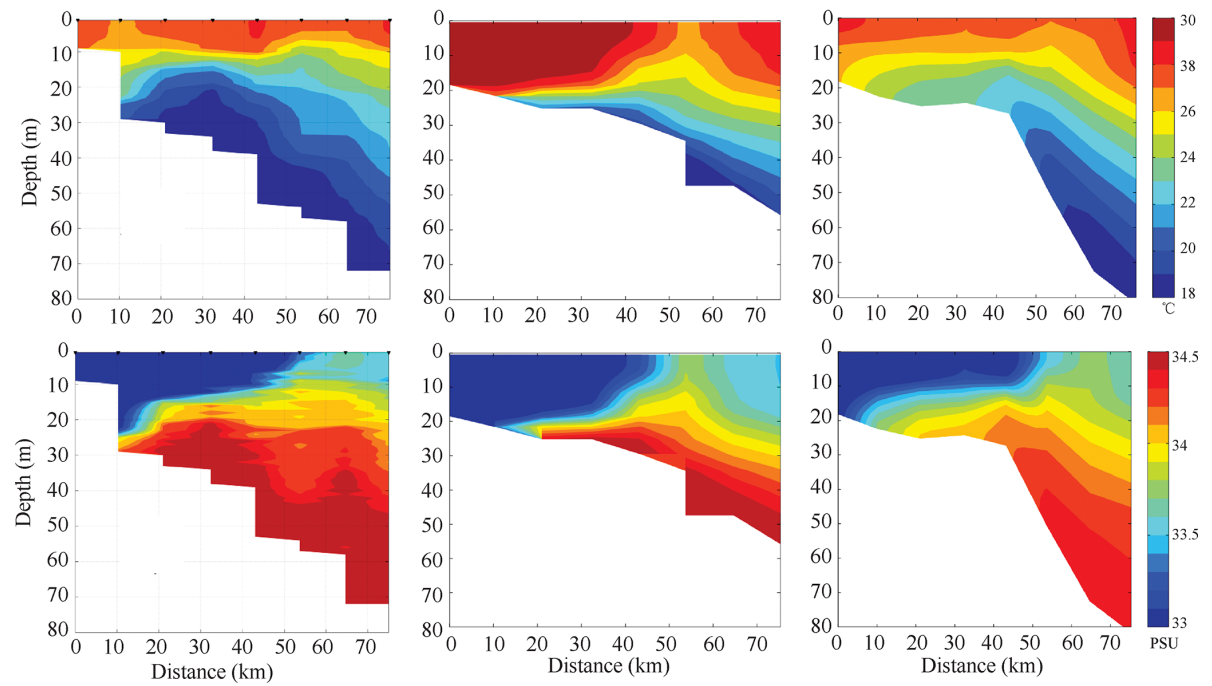

Figure 6. The vertical distributions of temperature (upper panels) and salinity (lower panels) along section E (see Fig. 1) from the in situ observations of Qiongdong cruise (left column), Mercator Océan (middle column), and SCSOFS (right column), respectively.

position of about $50 \mathrm{~km}$ from the coast for both in situ observations and SCSOFS, but at the position of about $40 \mathrm{~km}$ for MO. In the above, it is indicated that the results of SCSOFS are in better agreement with the in situ observations than those of MO.

The vertical distributions of TS from the in situ observations of Nansha cruise, and model results from MO, and SCSOFS along the $10^{\circ} \mathrm{N}$ section are shown in Fig. 7 for the layer of depth shallower than $300 \mathrm{~m}$ and Fig. 8 for the layer of depth from 300 to $1200 \mathrm{~m}$. Both systems have got almost the same vertical structures as the in situ observations, especially for the upper mixing layer depth about $70 \mathrm{~m}$ shown in the three results. Water temperature almost linearly decreases from 28 to $3^{\circ}$, with the depth going deep from the bottom of the upper mixing layer to $1200 \mathrm{~m}$ depth. However, salinity increases from 33.5 to $34.5 \mathrm{psu}$, with the depth going deep from the bottom of the upper mixing layer to about $200 \mathrm{~m}$ depth, and keeping almost constant at 34.5 psu from 200 to $300 \mathrm{~m}$. Then a freshwater layer exists in the middle layer from about 400 to $700 \mathrm{~m}$, with salinity of about 34.4 psu. Below the middle layer, the salinity again increases from 34.4 to $34.58 \mathrm{psu}$, with the depth increasing from 700 to $1200 \mathrm{~m}$. It indicates that the results of MO and SCSOFS are in good agreement with in situ observations, except that the salinity 

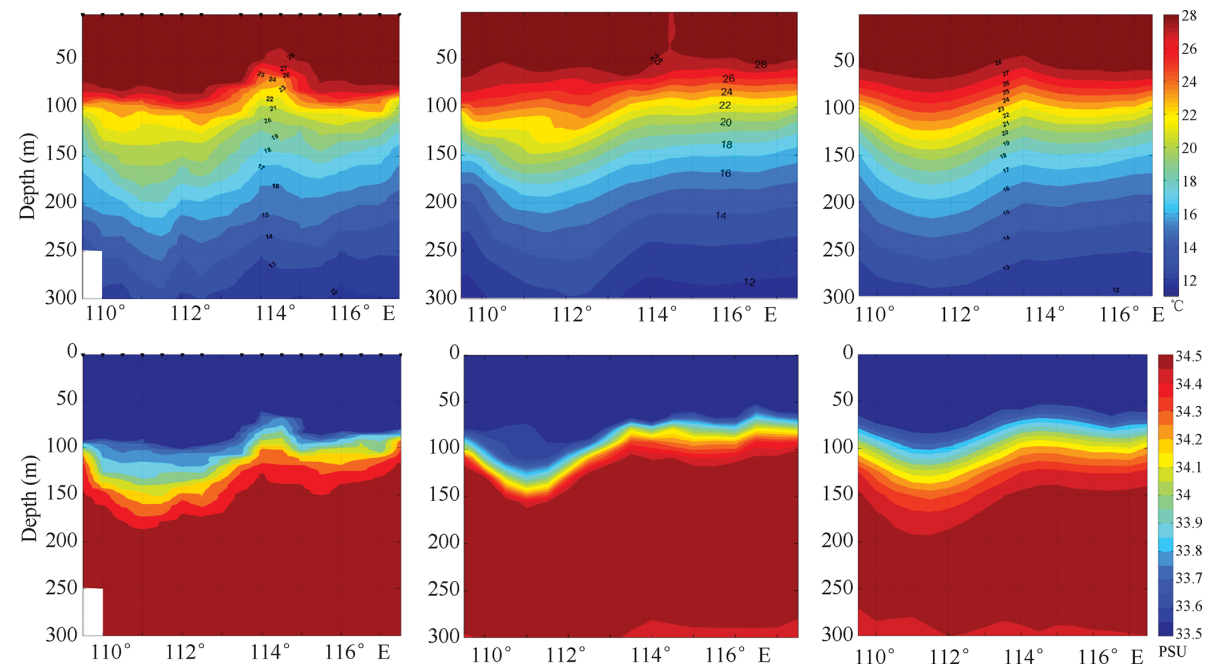

Figure 7. The vertical distributions of temperature (upper panels) and salinity (lower panels) for the layer of depth shallower than $300 \mathrm{~m}$ along the section $10^{\circ} \mathrm{N}$ from the in situ observations of Nansha cruise (left column), Mercator Océan (middle column), and SCSOFS (right column).
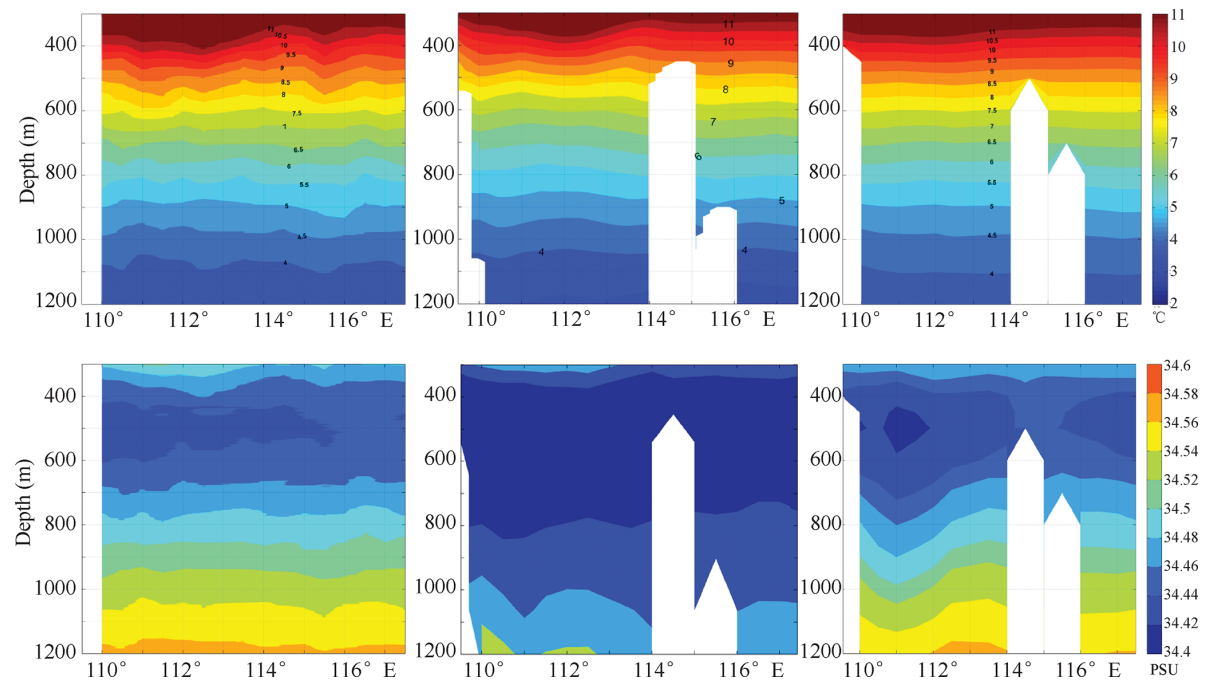

Figure 8. The same with Fig. 7, but for the layer of depth from 300 to $1200 \mathrm{~m}$.

of the freshwater in the middle layer from MO is less than 34.4 psu which is fresher than that of in situ observations and SCSOFS, but the thickness of the fresh layer is thicker than those of in situ observations and SCSOFS.

\subsubsection{Correlation analysis between model and in situ data}

In order to better compare and validate the performance of the two systems, we collected all the measured TS data from five cruises in the SCS in 2012 to conduct a comprehensive correlation analysis. Figure 9 shows the comparison of TS between the model results from MO and SCSOFS and the in situ observations by scatter points, respectively. Each point in the Fig. 9 corresponds to two values of temperature or salinity, one is from the in situ observations along the $x$ axis, and the other one is from the model results from MO or SCSOFS along the $y$ axis. The correlation coefficients of temperature are 0.987 and 0.982 , and those of salinity are 0.717 and 0.897 , between MO, SCSOFS, and in situ observations, above the $95 \%$ significance level, respectively. This shows the good relativity between MO, SCSOFS, and in situ observations. It also indicates that the relativity of temperature is in better agreement with in situ observations than that of salinity for both MO and SCSOFS, and SCSOFS is in better agreement with in situ observations than MO for salinity. 

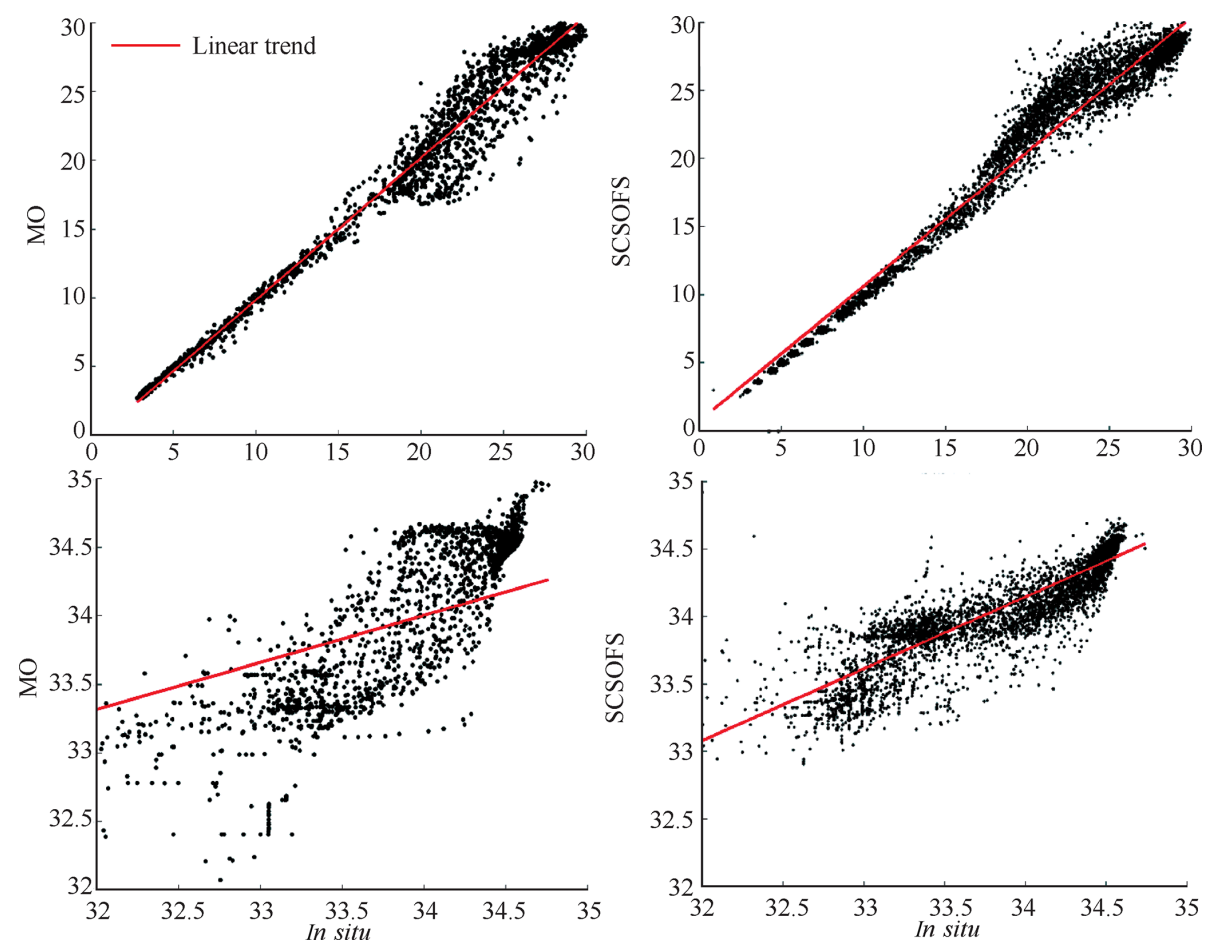

Figure 9. The relative relationships of temperature (upper panels) and salinity (lower panels) between Mercator Océan (left column), SCSOFS (right column), and the in situ observations of all cruises.

\subsection{Mesoscale activities}

\subsubsection{SST front}

Oceanic front is a good indicator for connection between water masses with different hydrological features, which is an important marine mesoscale phenomenon. There are numerous SST fronts in the SCS, most of them located on the continental shelf with the depth below $200 \mathrm{~m}$ or aligned with the shelf break, especially in the NSCS. A few obvious SST fronts have been identified from the long-term NOAA/NASA Pathfinder SST data, namely Fujian-Guangdong Coastal Front, Pearl River Estuary Coastal Front, Taiwan Bank Front, Kuroshio Intrusion Front, Hainan Island East Coastal Front, and Tonkin Gulf Coastal Front (Wang et al., 2001). All of them exhibit very strong seasonal variability, which is mainly due to the EAM (Belkin and Cornillon, 2003).

Figure 10 shows the distributions of SST fronts from the model results from MO and SCSOFS in four seasons. The similar frontal patterns with their evident seasonal variations are shown in both systems, except for small differences. In winter, most fronts reach maximum strength $\left(>0.2^{\circ} / \mathrm{km}\right)$. The Fujian-Guangdong Coastal Front and Taiwan Bank Front are major fronts in the SCS, which is in agreement with previous satellite results from Wang et al. (2001). These two fronts merge and extend to Pearl River Estuary and the island of Hainan. The Hainan Island East Coastal Front is stronger in MO than in SCSOFS, whereas the Tonkin Gulf Coastal
Front is stronger in SCSOFS than in MO. The Kuroshio Intrusion Front is obvious in SCSOFS; however, it is hardly seen in MO. In spring, most fronts become weak obviously due to the weakening of the northeastern monsoon for both operational systems, except that the Hainan West Coastal Front emerges in SCSOFS. In summer, weakening almost occurs in all the fronts mentioned above for SCSOFS, which is in good agreement with the results of Wang et al. (2001). However, disappearing occurs in all the fronts for MO. In fall, most fronts fade and disappear, except that the Taiwan Bank front has very weak strength compared to other seasons for both systems. Both systems have not shown the Kuroshio Intrusion Front identified by Wang et al. (2001) in summer and fall.

\subsubsection{Typhoon Tembin}

There are a lot of typhoons in the SCS during the typhoon season in every year; typhoon activity is very frequent in the SCS, especially in 2012. One important study on the airsea interaction is on the response of the physical ocean dynamics to typhoon in the oceanic upper layer. One important response is the decrease of SST due to the strong vertical mixing caused by the typhoon (Price et al., 1994). According to the SST observations from the satellite, SST usually decreases $2-5^{\circ} \mathrm{C}$ due to the typhoon passing (Cione and Uhlhorn, 2003; D'Asaro et al., 2007; Wu et al., 2008; Jiang et al., 2009). Dare and McBride (2011) studied the response 

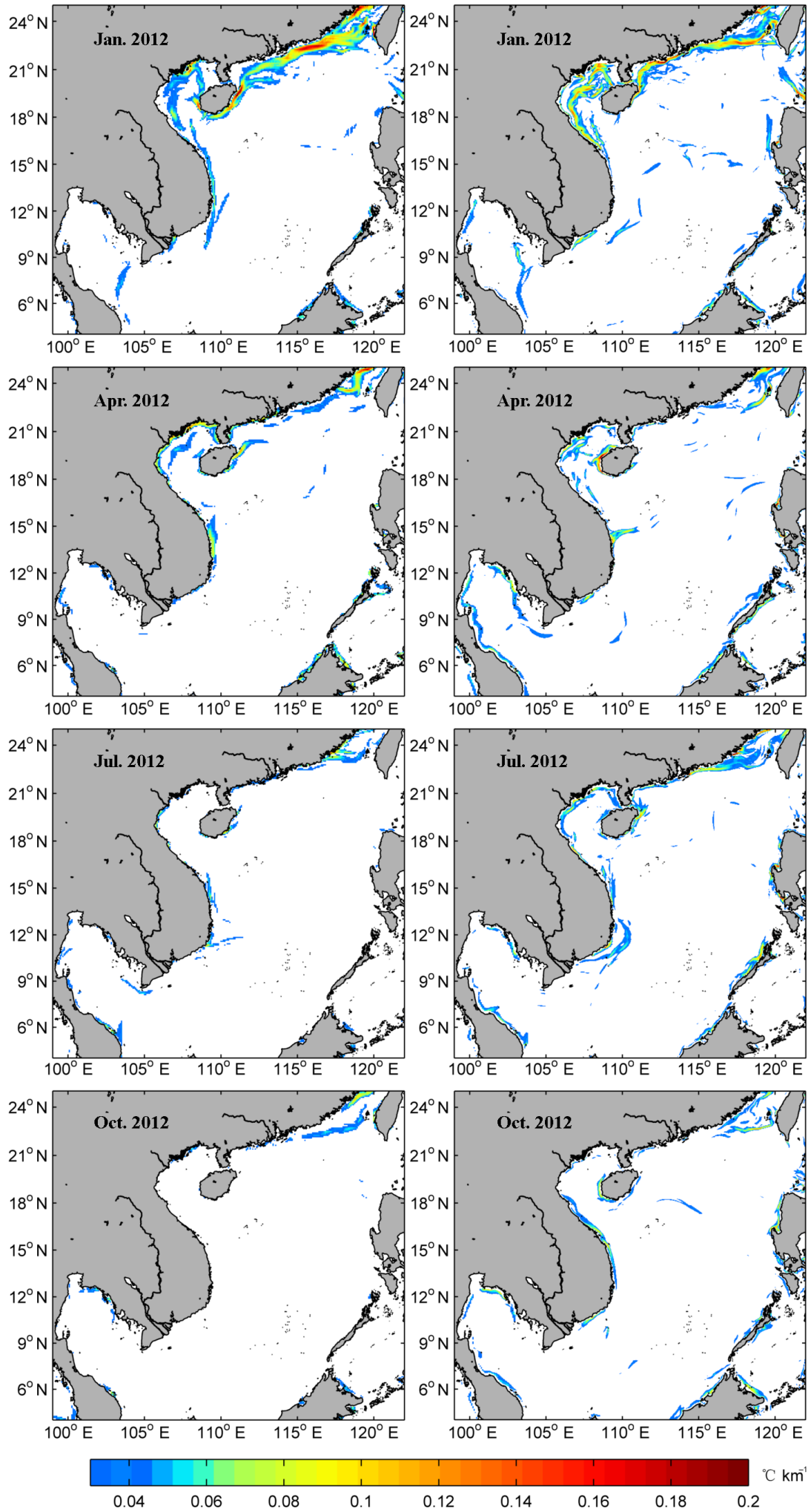

Figure 10. The distributions of SST fronts in the SCS from Mercator Océan (left panels) and SCSOFS (right panels) in January, April, July, and October 2012. 
Table 1. Number of eddies for different data types.

\begin{tabular}{l|ccc|ccc|ccc}
\hline & \multicolumn{3}{|c}{ AVISO } & \multicolumn{3}{c|}{ MO } & \multicolumn{3}{|c}{ SCSOFS } \\
\cline { 2 - 10 } & CYCL & ACYCL & Total & CYCL & ACYCL & Total & CYCL & ACYCL & Total \\
\hline Spring & 6 & 3 & 9 & 6 & 7 & 13 & 6 & 3 & 9 \\
Summer & 2 & 3 & 5 & 4 & 7 & 11 & 3 & 5 & 8 \\
Fall & 2 & 1 & 3 & 6 & 7 & 13 & 2 & 1 & 3 \\
Winter & 5 & 2 & 7 & 5 & 5 & 10 & 1 & 3 & 4 \\
Overall & 15 & 9 & 24 & 21 & 26 & 47 & 12 & 12 & 24 \\
\hline
\end{tabular}

of SST to the global typhoons during 1981-2008 and indicated that the maximum decrease of SST usually occurred 1 day after typhoon passing.

In this section, we selected Typhoon Tembin as an example to validate the MO and SCSOFS model skills for the SST simulations. As shown in Fig. 11, the Typhoon Tembin passed through and made a perfect turn in the NSCS from 25 to 28 August 2012. From the three results, we can find the obvious decrease of SST 1 day after the typhoon passed, which is about $2-4^{\circ} \mathrm{C}$ and in good correspondence with previous studies mentioned above. SCSOFS is in much better agreement with OISST than MO, especially on 26 and 27 August 2012, not only for the range of SST decrease, but also for the domain of SST decrease.

\subsubsection{Mesoscale eddies}

Mesoscale eddies cannot be identified and extracted from geophysical turbulent flow as observed by satellite altimetry without a suitable definition and a competitive identification algorithm. A number of different techniques for automatic identification of eddies have been proposed based either on physical or geometric criteria of the flow field. In this study, a free-threshold eddy identification algorithm with the SLA data is employed. This algorithm is based on the vector geometry method and Okubo-Weiss method (Okubo, 1970; Weiss, 1991) with six constraints applied to the SLA to detect an eddy. (1) A vorticity-dominated region at the eddy center ( $W<0$, here $W$ is the Okubo-Weiss parameter, for its definition referred as Xiu et al., 2010) must exist. (2) The SLA magnitude has a local extreme value (minimum or maximum). (3) Closed contours of SLA around the eddy center must exist. (4) The eddy radius must be larger than $45 \mathrm{~km}$. (5) The eddy amplitude must be larger than $4 \mathrm{~cm}$. In this study, the amplitude is defined as the absolute value of the SLA difference between the eddy center and the SLA along the eddy edge. The eddy-tracking method used is the one developed by Chaigneau et al. (2008), and we only keep eddies with a life span of no less than 28 days. Eddies were analyzed and compared based on MO, AVISO, and SCSOFS in 2012. The numbers of eddies for three types of data are in Table 1; cyclones and anticyclones were counted separately and seasonally.
The spatial distribution of eddy origin is shown in Fig. 12. MO shows more eddies, and especially more anticyclones formed than in AVISO; most of the excessive eddy cores were found near the middle of SCS. SCSOFS has more anticyclones as well and fewer cyclones than AVISO. Both MO and SCSOFS show excessive eddies formed in the middle of the basin and fewer eddies in the east of Vietnam. The SLA of SCSOFS and MO is calculated simply by subtracting mean SSH (14 years mean for SCSOFS and only 1-year mean for MO) instead of a uniformed mean sea surface, which might cause the excessive anticyclones in both models. Observations of AVISO and model results from MO and SCSOFS show that fewer eddies formed in the middle part of NSCS.

As for the seasonal distributions (figures not shown), all three data have most eddies in spring. Both AVISO and SCSOFS have fewer eddies in fall, and more cyclones than anticyclones in spring and fall, and all three have fewer cyclones than anticyclones in summer. SCSOFS differs with AVISO mainly in winter, while they agree reasonably in the other three seasons. MO has surplus eddies counted in every season especially for anticyclones, which might be the cause of the errors introduced by the simplified calculation of SLA.

\section{Conclusions}

Two operational ocean analysis and forecasting systems, MO and SCSOFS, have been built, based on the state-of-the-art hydrodynamic ocean models, ROMS and NEMO, in France and China, respectively. This paper demonstrated the results of comparison and validation for the performance of both systems on the ocean circulation, the structures of the TS, and mesoscale activities in the SCS, based on the observed satellite and in situ data in 2012. The comprehensive performances for the both systems are summarized as follows.

Both systems have capabilities to simulate the main basinscale circulations in the SCS and model results are in good agreement with the AVISO data. MO shows a better performance than SCSOFS in simulating several main branches of the SCS ocean circulations and eddies in January. SCSOFS did not generate many mesoscale or small-scale circulations, which may be caused by a small strong horizontal mixing set in the model. The westward intensification along the east- 

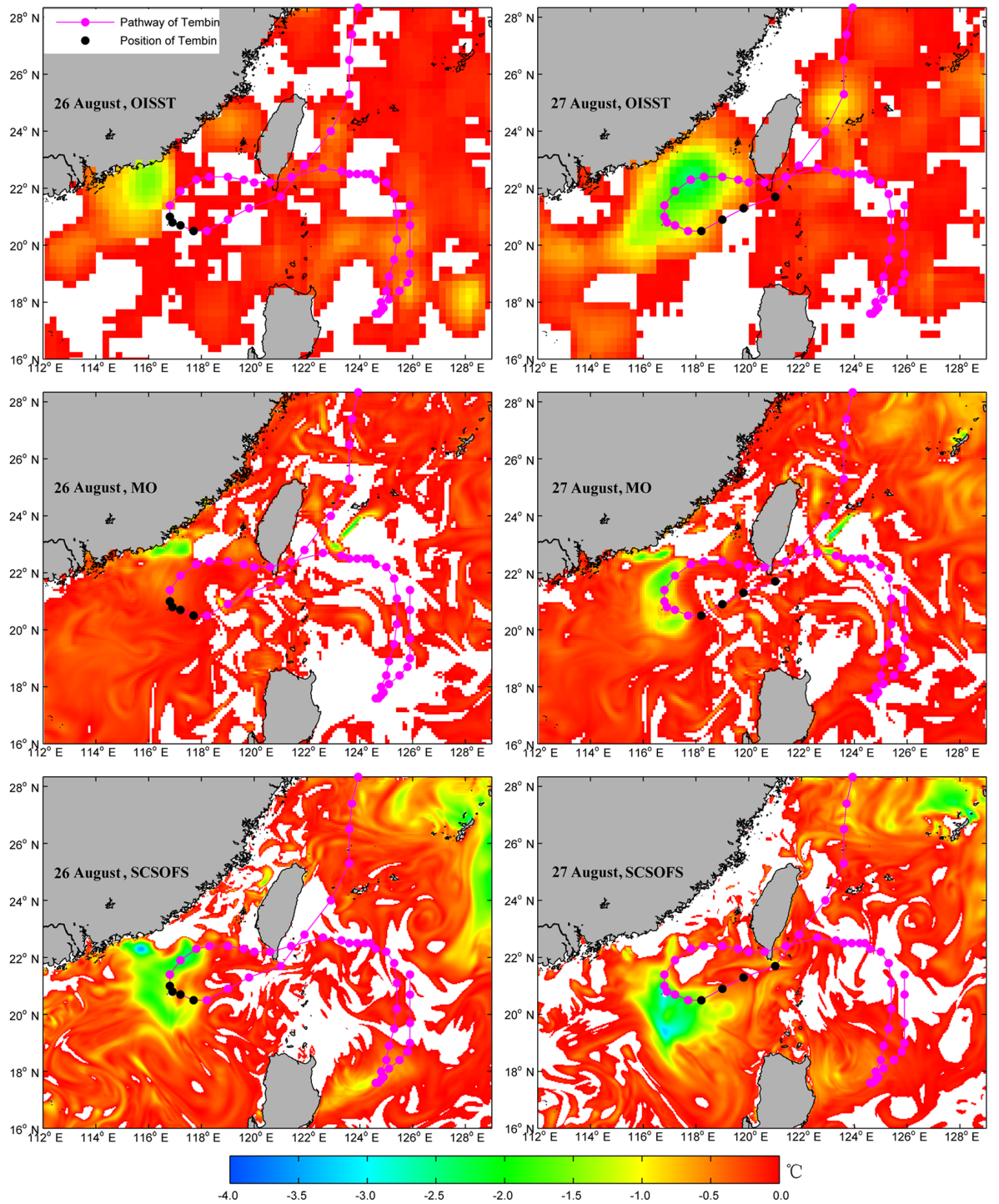

Figure 11. The SST differences of the day from the last day during the period of Typhoon Tembin. The black dots are the positions of the Typhoon Tembin at 00:00, 06:00, 12:00, and 18:00 UTC on each day.

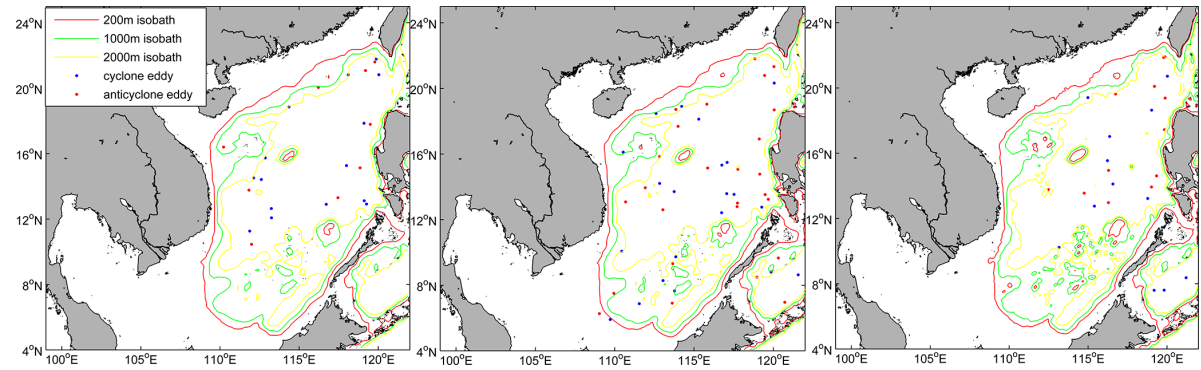

Figure 12. The spatial distributions of eddies' origins, identified using the method of Chaigneau et al. (2008) in the SCS from AVISO (left), Mercator Océan (middle), and SCSOFS (right) in 2012.

ern coast of Vietnam is the strongest in fall among the four seasons. For the type of the Kuroshio intruding the SCS, the AVISO observations, and model results from both MO and
SCSOFS, show the looping path in winter, the leaping path in summer, and the leaking path in fall. However, the leaking 
path, the looping path, and the leaping path are shown for AVISO, MO, and SCSOFS in spring.

Both systems demonstrated the similar variation trends in $u$ and $v$ components' time series with the mooring observation. The RMSEs between MO, SCSOFS, and mooring observations are 0.075 and $0.094 \mathrm{~m} \mathrm{~s}^{-1}$ for the $u$ component, and 0.062 and $0.084 \mathrm{~m} \mathrm{~s}^{-1}$ for the $v$ component. The results of $\mathrm{MO}$ are in better agreement with the observation than those of SCSOFS, especially during the period of Typhoon Kai-tak.

The maximum, minimum, and mean for the basinaveraged 12 monthly RMSEs between MO and MGDSST are 0.78, 0.37, and $0.51^{\circ}$, and between SCSOFS and MGDSST are $1.15,0.56$, and $0.86^{\circ}$ in the SCS, respectively. For the horizontal and vertical distributions of TS, both systems have achieved the same structures with the in situ data, but the results of SCSOFS are in better agreement with the in situ observations than those of MO. The correlation coefficients are 0.987 and 0.982 for temperature, 0.717 and 0.897 for salinity, between model results from MO and SCSOFS and in situ data, above the $95 \%$ significance level. It indicates the good relativity between MO, SCSOFS, and in situ observations; the relativity of temperature is in better agreement with in situ data than that of salinity for both model results from MO and SCSOFS, and the result from SCSOFS is in better agreement with in situ data than MO for salinity.

The similar SST frontal patterns with their evident seasonal variations are shown in both systems. Most fronts achieve maximum strength in winter, become weak, obviously due to the weakening of northeastern monsoon EAM in spring and summer, and fade and disappear in fall, which is consistent with the results of Wang et al. (2001).

During Typhoon Tembin in the NSCS, the obvious decrease of SST about $2-4^{\circ} \mathrm{C}$ occurs 1 day after the typhoon passed, shown in the results of MO, SCSOFS, and OISST, which is consistent with previous studies. SCSOFS is in much better agreement with OISST than MO for both the range and the domain of SST decrease.

MO has more eddies formed near the middle of SCS than AVISO, especially for anticyclones. SCSOFS has more anticyclones, but fewer cyclones than AVISO. AVISO data and model results from MO and SCSOFS all show most eddies in spring and fewer in fall, and fewer cyclones than anticyclones in summer. Both AVISO and SCSOFS have more cyclones than anticyclones in spring and fall.

In order to improve performance of MO and SCSOFS in the SCS in future based on the results of the comparison and validation for the two systems, some recommendations are proposed as below. For MO, we would like to suggest (1) modifying the model bathymetry in the coast area for the depth less than $200 \mathrm{~m}$ to improve the model performance in the shallow water area, such as the SST front; (2) changing the initial conditions of TS to improve the TS vertical structures, especially for the salinity in the deep water area. For SCSOFS, we would like to suggest (1) weakening horizon- tal mixing to get more reasonable mesoscale or small-scale circulations; (2) optimizing the data assimilation scheme further to better assimilate the in situ observations and satellite data; (3) replacing the surface forcing data with the higher horizontal or temporal resolution; (4) replacing the boundary conditions from monthly to weekly temporal resolution, or daily resolution, like MO. For both systems, we would also like to suggest trying to obtain and assimilate more observed data during the typhoon period to observe the typhoon process more exactly.

Author contributions. Xueming Zhu, Hui Wang, and Guimei Liu compared and validated the model results on velocities and TS. Charly Régnier and Marie Drévillon built the MO; Dakui Wang built the SCSOFS. Xiaodi Kuang analyzed the model results on mesoscale eddies. Shihe Ren analyzed the model results for the SST front. Zhiyou Jing provided the in situ data. Xueming Zhu prepared the manuscript with contributions from all co-authors.

Acknowledgements. We would like to thank the anonymous reviewers and the editor, Ivan Federico, for their valuable contributions that allowed us to improve the manuscript substantially. This study is supported by the National Natural Science Foundation of China under contract nos. 41222038, 41376016, and 41206023, and the Strategic Priority Research Program of the Chinese Academy of Sciences, grant no. XDA11020104 03.

Edited by: I. Federico

Reviewed by: L. Lusito and one anonymous referee

\section{References}

Amante, C. and Eakins, B.: ETOPO1 1 Arc-Minute Global Relief Model: Procedures, Data Sources and Analysis, NOAA Technical Memorandum NESDIS NGDC-24, National Geophysical Data Center, NOAA, Technical Memorandum NESDIS NGDC24, doi:10.7289/V5C8276M, 2009.

Antonov, J. I., Locarnini, R. A., Boyer, T. P., Mishonov, A. V., and Garcia, H. E.. World Ocean Atlas 2005, Volume 2: Salinity, edited by: Levitus, S., NOAA Atlas NESDIS 62, U.S. Government Printing Office, Washington, D.C., 182 pp., 2006.

Arakawa, A. and Lamb, V. R.: Computational design of the basic dynamical processes of the UCLA general circulation model, Methods of Computational Physics, 17, New York, Academic Press, 173-265, 1977.

Barnier, B., Siefridt, L., Marchesiello, P.. Thermal forcing for a global ocean circulation model using a three-year climatology of ECMWF analyses, J. Mar. Syst., 6, 363-380, 10.1016/09247963(94)00034-9, 1995.

Barnier, B., Madec, G., Penduff, T., Molines, J. M., Treguier, A. M., Le Sommer, J., Beckmann, A., Biastoch, A., Boning, C., Deng, J., Derval, C., Durand, E., Gulev, S., Remy, E., Talandier, C., Theetten, S., Maltrud, M., McClean, J., and De Cuevas, B.: Impact of partial steps and momentum advection schemes in a global circulation model at eddy permitting resolution, Ocean Dynam., 56, 543-567, 2006. 
Belkin, I. and Cornillon, P.: SST fronts of the pacific coastal and marginal seas, Pacific Oceanogr., 1, 90-113, 2003.

Blanke, B. and Delecluse, P.: Variability of the tropical AtlanticOcean simulated by a general-circulation model with 2 different mixed-layer physics, J. Phys. Oceanogr., 23, 1363-1388, 1993.

Cai, S. and Wang, W.: A numerical study on the circulation mechanism in the northeastern South China Sea and Taiwan Strait, Tropic Oceanol., 16, 7-15, 1997.

Carton, J. and Giese, B.: A Reanalysis of Ocean Climate Using Simple Ocean Data Assimilation (SODA). Mon. Weather Rev., 136, 2999-3017, doi:10.1175/2007MWR1978.1, 2008.

Caruso, M., Gawarkiewicz, G., and Beardsley, R.: Interannual variability of the Kuroshio intrusion in the South China Sea, J Oceanogr., 62, 559-575, 2006.

Chaigneau, A., Gizolme, A. and Grados, C.: Mesoscale eddies off Peru in altimeter records: Identification algorithms and eddy spatiotemporal patterns, Prog. Oceanogr., 79, 106-119, 2008.

Chao, S., Shaw, P., and Wang, J.: Wind relaxation as a possible cause of the South China Sea Warm Current, J. Oceanogr., 51, 111-132, 1995.

Chao, S., Shaw, P., and Wu, S.: Deep water ventilation in the South China Sea, Deep Sea Res. I, 43, 445-466, 1996.

Chern, C. and Wang, J.: A numerical study of the summertime flow around the Luzon Strait, J. Oceanogr., 54, 53-64, 1998.

Chern, C. and Wang, J.: Numerical study of the upper-layer circulation in the South China Sea, J Oceanogr., 59, 11-24, 2003.

Chern, C., Jan, S., and Wang, J.: Numerical study of mean flow patterns in the South China Sea and the Luzon Strait, Ocean Dynam., 60, 1047-1059, doi:10.1007/s10236-010-0305-3, 2010.

Chu, P. and Li, R.: South China Sea Isopycnal-Surface Circulation, J. Phys. Oceanogr., 30, 2420-2438, 2000.

Chu, P., Lu, S., and Chen, Y.: A Coastal Air-Ocean Coupled System (CAOCS) evaluated using an Airborne Expendable Bathythermograph (AXBT) data set, J. Oceanogr., 55, 543-558, doi:10.1023/A:1007847609139, 1999.

Cione, J. and Uhlhorn, E.: Sea surface temperature variability in hurricanes: Implications with respect to intensity change, Mon. Weather Rev., 131, 1783-1796, 2003.

CLS, SSALTO/DUACS User handbook: (M)SLA and (M)ADT Near-Real Time and Delayed Time Products. CLS-DOS-NT06-034, Issue 4.4, Nomenclature: SALP-MU-P-EA-21065-CLS, 2015.

Dare, R. and McBride, J.: Sea surface temperature response to tropical cyclones, Mon. Weather Rev., 139, 3798-3808, 2011.

D'Asaro, E., Sanford, T., Niiler, P., and Terrill, E.: Cold wake of hurricane Frances. Geophys. Res. Lett., 34, L15609, doi:10.1029/2007GL030160, 2007.

Du, Y., Yi, J., Wu, D., He, Z., Wang, D., and Liang, F.: Mesoscale oceanic eddies in the South China Sea from 1992 to 2012: evolution processes and statistical analysis, Acta Oceanol. Sin., 33, 36-47, doi:10.1007/s13131-014-0530-6, 2014.

Fang, G. and Zhao, B.: A note on the main forcing of the northeastward flowing current off the Southeast China Coast, Prog. Oceanog., 21, 363-372, 1988.

Fang, Y., Fang, G., and Yu, K.: ADI barotropic ocean model for simulation of Kuroshio intrusion into China southeastern waters, Chin. J. Oceanol. Limnol., 14, 357-366, 1996.

Farris, A. and Wimbush, M.: Wind-induced intrusion into the South China Sea, J. Oceanogr., 52, 771-784, 1996.
Fichefet, T. and Maqueda, M. A.: Sensitivity of a global sea ice model to the treatment of ice thermodynamics and dynamics, J. Geophys. Res., 102, 12609-12646, 1997.

Goosse, H., Campin, J. M., Deleersnijder, E., Fichefet, T., Mathieu, P. P., Maqueda, M. A. M., and Tartinville, B.: Description of the CLIO model version 3.0, Institut d'Astronomie et de Geophysique Georges Lemaitre, Catholic University of Louvain, Belgium, 2001.

Guan, B.: The warm current in the South China Sea - a current flowing against the wind in winter in the open sea off Guangdong province, Oceanol. Limnol. Sin., 9, 117-127, 1978.

Guan, B.: Winter counter - wind current off the south eastern China coast and a preliminary investigation of its source. Proceedings of the Symposium on the Physical and Chemical Oceanography of the China Seas, Beijing, China Ocean Press, 1-9, 1993.

Hellerman, S. and Rosenstein, M.: Normal monthly wind stress over the world ocean with error estimates, J. Phys. Oceanogr., 13, 1093-1104, 1983.

$\mathrm{Hu}$, J., Liang, H., and Zhang, X.: Sectional distribution of salinity and its indication of Kuroshio's intrusion in southern Taiwan Strait and northern South China Sea late summer, 1994, Acta Oceanologica Sinica, 18, 225-236, 1999.

Hu, J., Kawamura, H., Hong, H., and Qi, Y.: A review on the currents in the South China Sea: seasonal circulation, South China Sea Current and Kuroshio intrusion, J. Oceanogr., 56, 607-624, 2000.

Hu, J., Gan, J., Sun, Z., Zhu, J., and Dai, M.: Observed three dimensional structure of a cold eddy in the southwestern South China Sea, J. Geophys. Res., 116, C05016, doi:10.1029/2010JC006810, 2011.

Huang, Q., Wang, W., Li, Y., Li, C., and Mao, M.: General situations of the current and eddy in the South China Sea, Adv. Earth Sci., 7, 1-9, 1992.

Hunke, E. C. and Dukowicz J. K.: An elastic-viscous-plastic model for sea ice dynamics, J. Phys. Oceanogr., 27, 1849-1867, 1997.

Ji, Q., Zhu, X., Wang, H., Liu, G., Gao, S., Ji, X., and Xu, Q.: Assimilating operational SST and sea ice analysis data into an operational circulation model for the coastal seas of China. Acta Oceanol. Sin., 34, 54-64, doi:10.1007/s13131-015-0691-y, 2015.

Jiang, X., Zhong, Z., and Jiang, J.: Upper ocean response of the South China Sea to Typhoon Krovanh (2003), Dynam. Atmos. Oceans, 47, 165-175, 2009.

Jing, Z. Y., Qi, Y. Q., Du, Y., Zhang, S. W., and Xie, L. L.: Summer upwelling and thermal fronts in the northwestern South China Sea: Observational analysis of two mesoscale mapping surveys, J. Geophys. Res. Oceans, 120, 1993-2006, doi:10.1002/2014JC010601, 2015.

Kanamitsu, M., Ebisuzaki, W., Woollen, J., Yang, S., Hnilo, J., Fiorino, M., and Potter, G.: NCEP-DOE AMIP-II Reanalysis (R-2), B. Am. Meteor. Soc., 83, 1631-1643, doi:10.1175/BAMS-8311-1631, 2002.

Lellouche, J. M., Le Galloudec, O., Drévillon, M., Régnier, C., Greiner, E., Garric, G., Ferry, N., Desportes, C., Testut, C. E., Bricaud, C., Bourdalle-Badie, R., Tranchant, B., Benkiran, M., Drillet, Y., Li, R., Zeng, Q., Gan, Z., and Wang, W.: Numerical simulation of South China Sea Warm Current and currents in Taiwan Strait in winter, Prog. Nat. Sci., 3, 21-25, 1993. 
Li, L., Nowlin Jr., W. D., and Su, J.: Anticyclonic rings from the Kuroshio in the South China Sea, Deep-Sea Res. I, 45, 14691482, 1998a.

Li, W., Liu, Q. and Yang, H.: Principal features of ocean circulation in the Luzon Strait, Journal of Ocean University of Qingdao, 28, 345-352, 1998b.

Liang, W., Yang, Y., Tang, T., and Chuang, W.: Kuroshio in the Luzon Strait. J. Geophys. Res., 113, C08048, doi:10.1029/2007JC004609, 2008.

Liu, Q., Liu, C., Zheng, S., Xu, Q., and Li, W.: The deformation of Kuroshio in the Luzon Strait and its dynamics, Journal of Ocean University of Qingdao, 26, 413-420, 1996.

Locarnini, R. A., Mishonov, A. V., Antonov, J. I., Boyer, T. P., and Garcia, H. E. World Ocean Atlas 2005, Volume 1: Temperature. S. Levitus, Ed. NOAA Atlas NESDIS 61, US Government Printing Office, Washington, D.C., 182 pp., 2006.

Madec, G. and Imbard, M.: A global ocean mesh to overcome the North Pole singularity, Clim. Dynam., 12, 381-388, 1996.

Mao, Q., Shi, P., and Qi, Y.: Sea surface dynamic topography and geostrophic current over the South China Sea from Geosat altimeter observation, Acta Oceanol. Sin., 21, 11-16, 1999.

Nan, F., Xue, H., Chai, F., Shi, L., Shi, M. and Guo, P.: Identification of different types of Kuroshio intrusion into the South China Sea, Ocean Dynam., 61, 1291-1304, doi:10.1007/s10236-011-04263, 2011a.

Nan, F., He, Z., Zhou, H., and Wang, D.: Three long-lived anticyclonic eddies in the northern South China Sea, J. Geophys. Res., 116, C05002, doi:10.1029/2010JC006790, 2011b.

Nan, F., Xue, H., Chai, F., Wang, D., Yu, F., Shi, M., Guo, P., and Xiu, P.: Weakening of the Kuroshio intrusion into the South China Sea over the past two decades, J. Climate, 26, 8097-8110, doi:10.1175/JCLI-D-12-00315.1, 2013.

Nan, F., Xue, H., and Yu, F.: Kuroshio intrusion into the South China Sea: A review, Prog. Oceanogr., 137, 314-333, doi:10.1016/j.pocean.2014.05.012, 2015.

Okubo, A.: Horizontal dispersion of floatable particles in the vicinity of velocity singularity such as convergences, Deep Sea Res., 17, 445-454, 1970.

Pham, D. T., Verron, J., and Roubaud, M. C.: A singular evolutive extended Kalman filter for data assimilation in oceanography, J. Mar. Syst., 16, 323-340, 1998.

Price, J., Sanford, T., and Forristall, G.: Forced stage response to a moving hurricane, J. Phys. Oceanogr., 24, 233-260, 1994.

Qu, T.: Upper-layer circulation in the South China Sea, J. Phys. Oceanogr., 90, 1450-1460, 2000.

Qu, T., Mitsudera, H., and Yamagata, T.: Intrusion of the North Pacific waters into the South China Sea, J. Geophys. Res., 105, 6415-6424, 2000.

Rio, M. H. and Hernandez F.: A mean dynamic topography computed over the world ocean from altimetry, in situ measurements, and a geoid model, J. Geophys. Res., 109, C12032, doi:10.1029/2003JC002226, 2004.

Roullet, G. and Madec, G.: Salt conservation, free surface, and varying levels: a new formulation for ocean general circulation models, J. Geophys. Res., 105, 23927-23942, 2000.

Shapiro, R.: Linear Filtering, Math. Comput., 29, 1094-1097, 1975. Shchepetkin, A. and McWilliams, J.: The regional oceanic modeling system (ROMS): a split-explicit, free-surface, topography- following-coordinate oceanic model, Ocean Modell., 9, 347404, doi:10.1016/j.ocemod.2004.08.002, 2005.

$\mathrm{Su}$, J.: Overview of the South China Sea circulation and its dynamics, Acta Oceanol. Sin., 27, 1-8, 2005.

Takano, K., Harashima, A. and Namba, T.: A numerical simulation of the circulation in the South China Sea-preliminary results, Acta Oceanogr. Taiwanica, 37, 165-186, 1998.

Wang, D., Liu, Y., Qi, Y., and Shi, P.: Seasonal variability of thermal fronts in the northern South China Sea from satellite data, Geophys. Res. Lett., 28, 3963-3966, 2001.

Wang, D., Xu, H., Lin, J., and Hu, J.: Anticyclonic eddies in the northeastern South China Sea during winter 2003/2004, J. Oceanogr., 64, 925-935, 2008.

Wang, G., Su, J., and Chu P.: Mesoscale eddies in the South China Sea observed with altimeter data, Geophys. Res. Lett., 30, 2121 , doi:10.1029/2003GL018532, 2003.

Wang, G., Chen, D., and Su, J.: Winter eddy genesis in the Eastern South China Sea due to orographic wind jets, J. Phys. Oceanogr., 38, 726-732, 2008.

Wang, H., Wang, Z., Zhu, X., Wang, D., and Liu, G.: Numerical study and prediction of nuclear contaminant transport from Fukushima Daiichi nuclear power plant in the North Pacific Ocean, Chin. Sci. Bull. 57, 3518-3524. doi:10.1007/s11434012-5171-6, 2012.

Wang, J.: Global linear stability of the 2-D shallow-water equations: An application of the distributive theorem of roots for polynomials in the unit circle, Mon. Weather Rev., 124, 1301-1310, 1996.

Wang, J. and Chern, C.: The warm-core eddy in the northern South China Sea, I. Preliminary observations on the warm-core eddy, Acta Oceanogr. Taiwan, 18, 92-103, 1987.

Weiss, J.: The dynamics of enstrophy transfer in two dimensional hydrodynamics, Phys. D, 48, 273-294, 1991.

Williamson, G.: Hydrography and weather of the Hong Kong fishing ground, Hong Kong Fisheries Bulletin, 1, 43-49, 1970.

$\mathrm{Wu}, \mathrm{C}$. and Chiang, T.: Mesoscale eddies in the northern South China Sea, Deep Sea Res. II, 54, 1575-1588, 2007.

Wu, C., Shaw, P., and Chao, S.: Assimilating altimetric data into a South China Sea model, J. Geophys. Res., 104, 29987-30005, 1999.

Wu, C., Chang, Y., Oey, L., Chang, C., and Hsin, Y.: Air-sea interaction between tropical cyclone Nari and Kuroshio. Geophys. Res. Lett., 35, L12605, doi:10.1029/2008GL033942, 2008.

Wyrtki, K.: Scientific results of marine investigation of the South China Sea and Gulf of Thailand. Naga Rep. 2, 37-38, 1961.

Xiu, P., Chai, F., Shi, L., Xue, H., and Chao, Y.: A census of eddy activities in the South China Sea during 1993-2007, J. Geophys. Res., 115, C03012, doi:10.1029/2009JC005657, 2010.

Zhang, F., Wang, W., Huang, Q., Li, Y., and Chau, K.: Summary current structure in Bashi Channel. In Proceedings of Symposium of Marine Sciences in Taiwan Strait and Its Adjacent Waters, 65-72, China Ocean Press, Beijing, 1995.

Zhang, Z., Zhao, W., Tian, J., and Liang, X.: A mesoscale eddy pair southwest of Taiwan and its influence on deep circulation, J. Geophys. Res.-Ocean., 118, 6479-6494, doi:10.1002/2013JC008994, 2013.

Zhuang, W., Xie, S., Wang, D., Taguchi, B., Aiki, H., and Sasaki H.: Intraseasonal variability in sea surface height over the South China Sea, J. Geophys. Res., 115, C04010, doi:10.1029/2009JC005647, 2010. 